\title{
A política imperial em Quincas Borba: um diálogo entre a história e a literatura
}

Laila Correa e Silva

\section{Resumo}

Desenvolve-se uma breve análise histórica do romance-folhetim de Machado de Assis Quincas Borba, publicado pela revista feminina A Estação entre I886 e I89I, enfatizando as interlocuções sociais entre a obra machadiana e os debates parlamentares do final da década de I860 e meados da década de I880. Com isso, mostra-se que a política imperial e os impasses da Coroa para a promoção da reforma da escravidão são o centro de significação da narrativa de Quincas.

Palavras-chave: História do Brasil imperial - Literatura Brasileira - Machado de Assis - Quincas Borba - Memórias póstumas de Brás Cubas. 


\section{O Humanitismo do filósofo de Machado de Assis}

Quincas Borba foi publicado pela primeira vez em A Estação: jornal ilustrado para a família brasileira, entre I5 de julho de I886 e I5 de setembro de I89I. A Estação era uma publicação sobre modas editada pela tipografia H. Lombaerts \& Gia que mantinha também uma seção literária na qual Machado de Assis era uma "espécie de diretor espiritual" (MEYER, 200I, p. 66), dado que sua contribuição se dera desde a primeira edição, em I879 ${ }^{\mathrm{I}}$. A revista era uma continuação da publicação La Saison, revista francesa que circulou no Brasil entre I872 e I878. Nessa nova versão brasileira, A Estação pretendia produzir um periódico mais adequado aos leitores nacionais, com publicações que interessassem especialmente ao público feminino. O periódico teve grande sucesso e circulou na cidade do Rio de Janeiro até I904, com publicações quinzenais. A pretensão dos editores era, segundo o editorial de estreia de 15 de janeiro de I879, "criar um jornal brasileiro indispensável a toda mãe de família econômica que deseja trajar e vestir suas filhas segundo os preceitos da época"(A ESTAÇÃO, I879, p. I). As leitoras, portanto, encontravam moldes e riscos para costurar trajes adequados a várias ocasiões, dando continuidade ao perfil já adotado pela La Saison; contudo, a parte literária da edição brasileira foi uma novidade de $A$ Estação e propiciou a oportunidade de criar um espaço literário nacional. A inclusão da parte literária, que abordava ficção, belas artes, cultura e entretenimento, sinalizava a abertura do periódico para outros públicos além do feminino, por isso o subtítulo de jornal ilustrado para a família ${ }^{2}$.

A "parte literária" compunha-se de quatro páginas até I5 de agosto de I890; a partir dessa data, foram acrescentadas mais duas páginas à seção, que receberia um maior número de anúncios. Neste texto não traçarei as interlocuções entre Quincas Borba e as publicações da "parte literária" de AEstação ${ }^{3}$, e convido o leitor agora a percorrer o enredo de Quincas.

O folhetim de Machado de Assis narra os anos derradeiros da vida do filósofo e amigo de Brás Cubas, Joaquim Barbosa dos Santos, que formulou

I Machado de Assis publicou em A Estação, além de Quincas Borba, 37 contos, seis poemas, uma novela e outras publicações variadas, como críticas, resenhas, editoriais e traduções.

2 Para mais detalhes sobre o contexto da publicação em folhetim e as mudanças significativas entre o folhetim e a publicação em livro de Quincas Borba, ver: SILVA, Ana Cláudia Suriani. Machado de Assis: do folhetim ao livro. São Paulo: Editora Nversos, 2015.

3 Mais uma vez, indico o livro de Silva (2015). A autora aborda as mudanças que ocorreram entre a publicação em folhetins e a versão final em livro. Há também o site <http://www.machadodeassis. net/>, em que Ana Claudia Suriani da Silva e John Gledson disponibilizaram um estudo minucioso das mudanças ocorridas entre as duas versões, acrescida de nota crítica dos autores. 
o Humanitismo em Memórias póstumas de Brás Cubas, outro folhetim machadiano publicado na Revista Brasileira, em I880. Uma das personagens principais ao redor da qual se desenvolve toda a trama é Rubião, ex-professor e enfermeiro de Quincas Borba. Ele herdará toda a fortuna de Quincas e se mudará de Barbacena, Minas Gerais, para o Rio de Janeiro, onde encontrará dificuldades de adaptação à vida na Corte, sendo manipulado, principalmente, por Cristiano Palha e Sofia, um casal ambicioso e ávido pela ascensão social. A não adaptação de Rubião à vida de "capitalista" o levará a um quadro de loucura irreversível, findo com sua morte: solitária e sem dinheiro.

Quincas apareceu pela primeira vez na narrativa de Brás, como um amigo dos tempos da escola primária que se fazia de "imperador nas festas do Espírito Santo" (ASSIS, I997, p. 43-44, grifo nosso); era um menino gracioso, inteligente e abastado, contudo uma vida de misérias o transformou em "maltrapilho avelhantado" (ASSIS, I997, p. 99), um verdadeiro mendigo. Ainda que o amigo de Brás tivesse passado por situações difíceis, ele não manifestava uma "resignação cristã", tampouco "conformidade filosófica". A miséria teria atingido Quincas de tal modo que "lhe calejara a alma, a ponto de lhe tirar a sensação de lama. Arrastava os andrajos, como outrora a púrpura: com certa graça indolente". Brás Cubas mostrou disposição em ajudá-lo, arranjando-lhe "alguma coisa". Porém, Quincas Borba não queria trabalhar, desejara apenas dinheiro, e Brás lhe ofereceu "uma nota de cinco mil réis" dizendo ao amigo "”ois está em suas mãos ver outras muitas [...] Trabalhando". A resposta de Quincas não foi nada receptiva: "fez um gesto de desdém; calou-se alguns instantes" e depois disse que "não queria trabalhar" (ASSIS, I997, p. IOO). É possível captar uma concepção depreciativa do trabalho que permearia toda a narrativa de Brás Cubas, com seu ápice no capítulo final do romance: "coube-me a boa fortuna de não comprar o pão com o suor do meu rosto" (ASSIS, I997, p. 193).

Quincas expunha sua "filosofia da miséria"; depois, por meio de um abraço em Brás, furtou-lhe o relógio do bolso. Brás, então, refletiu sobre a necessidade de regenerar Quincas Borba, de o "trazer ao trabalho e ao respeito de sua pessoa" (ASSIS, 1997, p. I02). No capítulo CIX, porém, descobriremos que Quincas "herdara alguns pares de contos de réis de um velho tio de Barbacena" (ASSIS, 1997, p. I5I). Sem qualquer esforço, o filósofo obtivera dinheiro e pôde, enfim, formular o Humanitismo, filosofia destinada a arruinar todos os outros sistemas filosóficos. Esse sistema exposto em Memórias póstumas de Brás Cubas e em Quincas Borba é "o princípio das coisas", "substância original" que se multiplica e se manifesta em todos os homens e em todas as coisas: "repartido e resumido em cada homem" (ASSIS, I997, p. I58-I59). 
Essa filosofia foi aplicada por Quincas a suas observações sobre a organização social do Brasil. Para nós, leitores atuais, ela converte-se em uma justificativa patriarcal para as mazelas sociais do Brasil Império, estruturado pela instituição da escravidão.

A exposição mais prática dessa filosofia foi proferida por seu próprio autor em Quincas Borba, capítulo VI, numa conversa entre o filósofo e Rubião. Quincas falava da morte da avó, vítima de um desastre no largo do Paço, e concluía que a tragédia poderia ter se abatido sobre qualquer outra pessoa ou qualquer outra coisa: daria na mesma, pois, segundo Quincas, "o primeiro ato dessa série de atos foi um movimento de conservação: Humanitas tinha fome" (ASSIS, I89I, p. II). Isso dera ensejo para o filósofo falar sobre o que é a morte e a vida, a saber: manifestações de Humanitas, ou o princípio indestrutível, que "resume o universo e o universo é o homem" (ASSIS, I89I, p. I3). Rubião não entendera muito bem a explanação filosófica sobre a manifestação de Humanitas e a morte da avó de Quincas, por isso este tentava explicitar a ideia (ASSIS, I89I, p. I4).

Rubião ouvia a inflamada palestra filosófica e ainda encontrara fôlego para questioná-la: "Mas, e a opinião do exterminado?”. A réplica do filósofo se segue como consequência de sua premissa: "Não há exterminado. Desaparece o fenômeno; a substância é a mesma. Nunca viste ferver água? Hás de lembrar-te que as bolhas fazem-se e desfazem-se de contínuo, e tudo fica na mesma água. Os indivíduos são essas bolhas transitórias”. Ainda assim, Rubião tenta questionar: "Bem; a opinião da bolha..."; mas o filósofo continua, abruptamente: "Bolha não tem opinião" (ASSIS, I89I, p. I5). Nesse ponto inicial da narrativa, Rubião se identificara com o vencido. Era um pobre trabalhador que já havia lecionado e tentado a sorte em outros ofícios. Para ele, era difícil penetrar a lógica do discurso de Quincas; assim como o africano transportado de Angola, Rubião integrava uma cadeia de "esforços e lutas" compostos com a única finalidade de servir a pessoas como Quincas. O Humanitismo, nesse contexto, é um recurso complexo. Ele atribui caráter de necessidade aos atos cometidos pela pura manifestação da vontade patriarcal, como se pode observar na falta de qualquer justificativa plausível nos argumentos arbitrários apresentados por Quincas Borba.

Para Magalhães Azeredo, autor de uma longa crítica publicada em $O$ Estado de S. Paulo - contemporânea à publicação de Quincas -, o Humanitismo ditou que "todas as complicações se resolvem pela regra de Hobbes: o mais forte devora o mais fraco; logo, a maior felicidade é ser forte, descender do peito ou dos rins de Humanitas; a única desgraça é não ter nascido" (GUIMARÃES, 20I2, p. 356). A identificação realizada por um leitor contemporâneo entre 
o Humanitismo e a filosofia de Thomas Hobbes exposta em Leviatã ou matéria, forma e poder de um Estado Eclesiástico e Civil (I935, tradução própria) é sugestiva. A despeito da simplificação da tese hobbesiana realizada por Azeredo, de fato existem alguns pontos em comum entre a tese do filósofo fictício de Machado de Assis e a filosofia política de um dos principais teóricos do Absolutismo, sobretudo no que concerne à composição da sociedade.

Segundo Hobbes, a sociedade ou Estado é um corpo artificial complexo; ele usa a metáfora do Leviatã, monstro marinho citado na Bíblia, um gigante coroado e com o corpo formado por milhares de homenzinhos. Com a mão direita, o monstro segura uma espada, simbolizando o poder temporal, e com a direita, uma cruz episcopal, símbolo do poder espiritual. Tal figura é bem semelhante à descrição de Humanitas no capítulo CXVII de Memórias Póstumas: a distribuição dos homens conforme as diferentes partes do corpo de Humanitas, seguindo para tanto a "grande lei do valor pessoal". Assim, "descender do peito ou dos rins de Humanitas [...] é ser um forte", o que é diferente de "descender dos cabelos ou da ponta do nariz" (ASSIS, I997, p. I58). Isso, em Hobbes, corresponderia grosso modo à gênese de formação do Estado ou da sociedade 4 . Hobbes buscava conferir legitimidade ao poder absoluto do monarca, argumentando que o homem apenas poderia viver em paz e em sociedade se concordasse em se submeter ao poder político absoluto do soberano; Quincas, por seu turno, utilizara Humanitas para justificar a desigualdade social e a negação de direitos às "bolhas transitórias", e tal consequência de seu sistema filosófico fica mais clara quando se apontam outras influências filosófico-teóricas no Humanitismo.

Araripe Junior, outro contemporâneo, identificou na filosofia de Quincas, no que concerne à luta pela sobrevivência, "os paradoxos de Xenófanes, de Parmênides, de Górgias, de Leontium e tantos outros célebres sofistas da antiguidade grega". Todavia, as referências mais interessantes que Araripe encontrou são as duas filosofias do século XIX "que mais se tem hostilizado" (GUIMARÃES, 2012, p. 366), o positivismo do filósofo francês August Comte e a teoria do naturalista britânico Charles Darwin, esta inspiradora do darwinismo social e do evolucionismo. Segundo o crítico, Quincas preten-

4 Thomas Hobbes argumenta, na "Introdução" de Leviatã, que no Estado a soberania é uma alma artificial, pois dá vida e movimento a todo o corpo; os magistrados e outros funcionários judiciais ou executivos, juntas artificiais; a recompensa ou o castigo (pelos quais, ligados ao trono da soberania, juntas e membros são levados a cumprir seu dever) são os nervos; a riqueza e a prosperidade de todos os membros individuais constituem a força; os conselheiros, por meio dos quais todas as coisas necessárias lhe são sugeridas, são a memória; a justiça e as leis, razão e vontade artificiais. 
dera que aqueles dois sistemas se conectassem. No caso do discurso filosófico construído por Machado de Assis, por meio do Humanitismo de Quincas, visava-se a refletir sobre como teorias científicas e filosóficas populares no Brasil a partir do final da década de I870 tinham a capacidade de construir um discurso superficial e, ao mesmo tempo, perigoso, para sustentar hierarquias e desigualdades sociais. Deve-se notar que a preocupação de Machado em abordar esse tipo de discurso filosófico reflete, também, um compromisso literário.

Segundo Roberto Schwarz (2000, p. I04), o Humanitismo, como o próprio nome sugere, consiste em uma sátira ao nascimento oitocentista de ismos, com alusão explícita à religião comteana da humanidade. O crítico também identifica outras filiações filosóficas, pois, no lugar de princípios positivistas, o Humanitismo aponta a luta de todos contra todos, ao modo descrito pelo darwinismo social. Sidney Chalhoub acredita que os conceitos derivados do darwinismo são o centro do Humanitismo. Para o historiador, o darwinismo social seria a sua grande preocupação, o que não descarta o ecletismo filosófico de Quincas e o recurso ao positivismo. Contudo, no contexto da década de I880, com a intensificação das lutas políticas pela emancipação dos escravizados, o darwinismo social como base do Humanitismo significaria, na perspectiva machadiana, um alerta para o "potencial ideologicamente racista do reducionismo biológico" (CHALHOUB, 2003, p. 45).

Além disso, também se pode notar uma crítica machadiana mais pontual e refinada, por meio do Humanitismo, que faria referência alegórica ao suposto Absolutismo exercido por D. Pedro II, sobretudo em relação à sua escolha voluntariosa de gabinetes e ao processo eleitoral como um todo, questões que foram debatidas com especial atenção pelos liberais após a queda do Gabinete composto pelo liberal Zacarias, em I868.

\section{A construção da alegoria política machadiana: Pedro Rubião de Alvarenga e Napoleão III}

O processo de enlouquecimento de Rubião pode ser analisado como um recurso alegórico ${ }^{5}$ utilizado por Machado para interpretar o contexto político

5 A relação entre o texto e a realidade é um tema caro à teoria literária e tem sido tópico de debate desde a Poética de Aristóteles. De modo geral, a alegoria é a metáfora como tropo de pensamento. Ela consiste na substituição do pensamento em causa por outro pensamento ao qual está ligado, numa re- 
brasileiro, por meio de acontecimentos franceses ligados à figura de Napoleão III (I808-I873), primeiro presidente da Segunda República francesa e imperador dos franceses no Segundo Império Francês, por meio de um golpe de estado em I85I. O recurso a essa figura da política francesa é explicitado a partir de uma análise do contexto político e social do Brasil, à época referida pela narrativa, bem como da leitura de aspectos narrativos desse folhetim.

Trata-se da análise de um período político muito importante, mas dotado de indeterminação quanto aos rumos futuros do país, especialmente em relação à questão do "elemento servil". O capítulo LVIII de Quincas marcou o envolvimento de Rubião na política nacional. Nesse momento, o ignaro personagem narra a sessão que decidiu pela queda do Gabinete Liberal chefiado pelo conselheiro Zacarias de Góis e Vasconcelos, em julho de I868, refletindo uma crise aguda da Coroa e um impasse sobre os rumos da "questão do elemento servil"; embora tudo seja descrito ironicamente pelo narrador.

Em I6 de julho de 1868 deu-se o desenlace de uma grande disputa, referente à Fala do Trono de maio de I868, informando "a nação de que a questão da escravatura fora objeto de um 'assíduo estudo' e de que uma proposta seria submetida à Assembleia, para sua consideração, 'oportunamente'" (CONRAD, I978, p. IOO). É notável nessa fala de I868 a posição cautelosa ou, no limite, dúbia de D. Pedro II. Segundo Sidney Chalhoub, essa linguagem "cautelosa" do Monarca poderia indicar "a disposição em esperar pelo fim da guerra" do Paraguai e "talvez sugira, quanto aos eventos que se seguiram, impaciência em dar fim àquela guerra". Todavia, ao que tudo indica, "Sua Majestade Imperial aderiu à arte de bordejar" (CHALHOUB, 2007, p. I55), isto é, reconhecia que alguma atitude deveria ser tomada para a promoção da emancipação, contudo hesitava ou protelava qualquer medida que pudesse abalar abruptamente o status quo. Ao aceitar a renúncia do liberal Zacarias, supostamente disposto à promoção da reforma servil, e nomear outro chefiado pelo conservador visconde de Itaboraí, que era claramente hostil ao projeto de reforma do elemento servil, D. Pedro II criou uma situação extremamente tensa que repercutiu em reações ferrenhas por parte dos liberais.

Machado de Assis convida-nos a uma interpretação do fato em seus desdobramentos. Assim, posto que o processo de loucura vivenciado por Rubião ocorrera lado a lado com as incertezas e os conflitos políticos que se su-

lação de semelhança, a esse mesmo pensamento. Se no símbolo, esquematicamente, forma e conteúdo são indissociáveis, se o símbolo é "aparição sensível" e natural da ideia, na alegoria a relação entre a ideia e as imagens que devem suscitá-la é externa e do domínio da convenção. 
cederam entre I868 e I87I, no enredo mesmo do romance, de modo geral a chave essencial da "mente política" descrita por Machado é o "napoleonismo universal, que ele via como uma consequência necessária do mundo reprimido do Império em seu período de 'Conciliação'”. Assim, a identificação criada entre Rubião e Napoleão III seria inteiramente apropriada ao tema machadiano, especialmente porque Luís Napoleão era apenas uma imitação de seu (suposto) tio. Segundo Gledson, existiria ainda outra dimensão política para essa identificação: Machado fez coincidir a queda do último Império europeu, prolongando a loucura de Rubião até os anos de I870 e I87I, com uma crise fundamental do único Império na América. Tal crise, argumenta o crítico, "mostrava que sua queda era só questão de tempo", por isso Gledson sugere que "a identificação com Napoleão III não surgiu na imprensa senão depois da queda final do Império em I889" (GLEDSON, I99I, p. IO4-IO5).

O senador liberal José Tomás Nabuco de Araújo, principal figura da política nacional nesse período, havia permanecido "quase silencioso" durante o ministério de Zacarias, porém no dia I7 de julho de I868, quando se apresenta no Senado o Ministério Conservador, o liberal "rompe o debate". A atitude do político liberal teria sido um "movimento espontâneo, puro, desinteressado", reflexo de uma compreensão "nítida [...] da realidade do nosso sistema político, que nunca foi, nem podia ser, outra coisa, em falta de eleições verdadeiras, senão a alteração dos partidos no governo a contento do Imperador" (NABUCO, I997, p. 763).

O conselheiro José Bonifácio, como disse Rubião no capítulo LVIII, também se pronunciou, apresentando uma moção em I7 de julho de I 868 seguindo a mesma perplexidade manifestada por Nabuco de Araújo. Mas foi o "Discurso do sorites de I7 de julho de I868", proferido por Nabuco de Araújo, que marcou a sessão do dia I7. Nele o senador atacou frontalmente a atitude de D. Pedro II ao substituir o Ministério Liberal, acusando diretamente a Coroa de Absolutista:

[...] tenho apreensões de um governo absoluto; não de um governo absoluto de direito, porque não é possível neste país que está na América, mas de um governo absoluto de fato. [...] quero apenas fazer um protesto [...] não sobre a legalidade do ministério atual, porque em verdade a Coroa tem o direito de nomear livremente os seus ministros, mas sobre a sua legitimidade. A escravidão, verbi gratia, entre nós é um fato autorizado por lei, é um fato legal, mas ninguém dirá que é fato legítimo, porque é um fato condenado pela lei divina, é um fato condenado pela civilização, é um fato condenado pelo mundo inteiro. 
Dizia Santo Agostinho que a Providência era tão grande que não permitia o mal senão porque era tão poderosa que dele derivava o bem. O bem a que eu aludo, senhores, é a unidade do partido Liberal, é a concentração de todas as forças democráticas no sentido de salvar o sistema representativo, que entre nós está em manifesta decadência (NABUCO, I997, p. 764).

A plateia que ouvira Nabuco de Araújo não deixaria passar despercebida a alusão do senador sobre a escravidão como fato legal, porém ilegítimo. Nabuco de Araújo chamava os liberais históricos e progressistas à unidade em função da luta contra a "ilegitimidade" dos atos da Coroa, que atacava o sistema representativo. O discurso de Nabuco de Araújo e sua menção a Santo Agostinho e ao argumento sobre a Providência referido nas Confissões, associado também à ilegitimidade da escravidão, acrescenta maior refinamento e erudição ao pronunciamento do senador liberal sobre a necessidade de união entre os liberais. Numa leitura mais superficial, a citação parece ser mero exercício retórico ${ }^{6}$. Há de se notar que Santo Agostinho apresentou uma justificativa "divina" para a escravidão, ao argumentar ser ela parte da punição pela perda humana de seu estado de graça. Segundo o filósofo, "a escravidão era um remédio [...] para o pecado, e Deus era quem tinha a responsabilidade direta de apontar tanto os senhores quanto os escravos" (DAVIS, 200I, p. IO7). Esse aspecto recuperado por Nabuco de Araújo, sintetizado na referência a Santo Agostinho, porém, não fugiu à pena de Machado de Assis: no capítulo IX do folhetim e no capítulo X do livro Quincas Borba, narra que Rubião recebera uma carta de Quincas, enviada do Rio de Janeiro. Na carta endereçada a Rubião, Quincas Borba dizia que era Santo Agostinho:

[...] Sou Santo Agostinho; descobri isto anteontem; ouça e cale-se. Tudo coincide em nossas vidas [...] ele pensava, como eu, que tudo que existe é bom, e assim o demonstra no capítulo XVI, livro VII das Confissões, com a diferença que para ele, o mal é um desvio da vontade, ilusão própria de um século atrasado, concessão ao erro, pois que o mal nem mesmo existe, e só a primeira afirmação é verdadeira; nem todas as cousas são boas, omnia bona, e adeus (ASSIS, I89I, p. 22-23).

6 Segundo a exposição de Santo Agostinho nas Confissões, o Mal é a ausência do Bem. Depois do pecado original, Deus teria castigado os seres humanos, tirando-lhes o poder de seguir a vontade Dele, que significava, para Agostinho, fazer o Bem. Por isso, os seres humanos não podem mais fazer o Bem, isto é, seguir a vontade de Deus, ainda que o queiram fazer. 
Com o delírio filosófico de Quincas Borba, pode-se dizer que Machado de Assis refere-se à distinção entre legalidade e legitimidade, ao temor do absolutismo praticado pela Coroa e ao sorites constitucional do discurso de I7 de julho, que tiveram papel de destaque na imprensa política (NABUCO, I997, p. 768). Raymundo Faoro argumenta que "o dom Pedro de Machado de Assis está coroado com o mito, que o eleva, nas ruas, no coche, no jogo político". Ele "domina as imaginações, frequenta os sonhos e se esgueira na fantasia". Para além de criar ministérios e "sugerir" os governantes das províncias, Machado teria abordado o "mito do bom velho dom Pedro" que viveu na "imaginação popular" (FAORO, 200I, p. 69)7. Mas o mito teria se convertido em poder pessoal, conforme as denúncias do Partido Liberal.

O princípio de que o rei reina e não governa foi sustentado por Nabuco de Araújo na sessão de I8 de julho de I868, quando foi decidida a dissolução da Câmara. Joaquim Nabuco afirma que o senador liberal "procura aproveitar-se de todas as ocasiões, de todos os pretextos, para trazer a campo a grande questão, para não deixar que nenhuma outra distraia dela a atenção do Senado, do partido Liberal, e, principalmente, do Imperador" (NABUCO, I997, p. 776). Ao mesmo tempo, Nabuco e Saraiva reconheciam que o governo pessoal do imperador tinha o seu papel e sua posição enquanto representante da nação brasileira, contudo o que era combatido era o poder ditatorial da Coroa, resultante de não estar a vez dos partidos entregue ao eleitorado, mas ao poder moderador. Trata-se, evidentemente, da leitura realizada por Joaquim Nabuco sobre o período político referido ${ }^{8}$.

Segundo tais discursos, isso não seria culpa do imperador, mas sim a manifestação dos vícios, da intolerância e da cobiça dos próprios partidos. Todavia, a "massa partidária" não entendia a distinção feita por Nabuco e Saraiva entre o imperador e a "ordem das coisas", situação na qual o próprio monarca

7 Nesse aspecto, Schwarcz (I998) argumentou que a figura de D. Pedro II foi alvo de uma grande quantidade de imagens e de representações, de tal modo que o "corpo do rei" simbolizava duas instâncias: a criação política e institucional de realeza e a figura mítica, marca do imaginário popular.

8 A historiografia que abordou a composição e articulação da política imperial apontou a complexidade do jogo político travado entre elites econômicas, elites políticas, partidos (conservador e liberal) e o poder imperial. Um pouco distante da visão de um absolutismo da monarquia, presente na argumentação dos liberais à época, a historiografia revela uma dinâmica de concessões, disputas e rearranjos entre os partidos, as elites econômicas e o imperador, demonstrando que o poder imperial não era soberano, mas se articulava em função das demandas locais de uma elite econômica que, no mais das vezes, constituía a base das elites políticas, liberal e conservadora. Trata-se de uma discussão historiográfica longa. Devido à limitação deste artigo, apontarei apenas os principais nomes da historiografia sobre a política imperial: Miriam Dolhnikoff, Ilmar de Mattos e José Murilo de Carvalho. 
era "a primeira vítima inocente"; eles responsabilizavam pessoalmente a Coroa, na qual viam usurpação (NABUCO, I997, p. 779).

Saraiva manifestara em carta de 24 de dezembro de I868 sua inteira concordância com as propostas de Nabuco, e resumiu a missão imediata do Partido Liberal em dois pontos: a emancipação dos escravos e a reforma eleitoral. Saraiva relembra o discurso de Nabuco de Araújo em I7 de julho, que destacou o poder ditatorial da Coroa na direção dos negócios públicos, e complementa:

Que o sr. dom Pedro II tem fato um poder igual ao de Napoleão III, é outra verdade de que estou profundamente convencido. A constituição francesa, porém, é a base do poder daquele monarca, ao passo que o falseamento do voto é a origem do excessivo poder do Imperador do Brasil.

Que esse excesso de poder é fatal à Monarquia [...] é ainda uma verdade que os fatos estão diariamente demonstrando (NABUCO, I997, p. 78I).

A referência a Napoleão III no centro do debate político entre oposição liberal e Gabinete Conservador, escolhido por D. Pedro II, dá um importante elemento para a análise da alegoria política montada por Machado de Assis em Quincas Borba. Sobretudo, em relação à hipótese aqui aventada: de que a menção a Napoleão III se refere ao contexto político e social específico do Brasil Império. John Gledson lança luz a esse aspecto, ligando a loucura de Rubião (imaginar-se Napoleão III) ao procedimento e desenvolvimento estrutural de Quincas Borba; "a loucura de Rubião se coloca no centro do romance, dando-lhe a organização temática e estrutural" (GLEDSON, I99I, p. I02). Assim, dados o contexto da rearticulação política descrita, entre I868 e I87I, e a discussão sobre os rumos da escravidão, pode-se construir um percurso em Quincas Borba que revela a instabilidade e o conflito da Coroa quanto ao modo de condução do processo de emancipação, ligando a política à literatura, retomando temas espinhosos da política imperial da década de I870 num contexto de crise e queda da monarquia nos anos I 880 .

\section{Referências}

A ESTAÇÃO: jornal ilustrado para a família. Rio de Janeiro: H. Lombaerts \& Cia. I879-I892.

ASSIS, Machado de. Quincas Borba. Rio de Janeiro: B. L. Garnier Livreiro-Editor, I89I.

ASSIS, Machado de. Memórias póstumas de Brás Cubas. São Paulo: FTD, I997. 
GALDWELL, Helen. O Otelo Brasileiro de Machado de Assis: um estudo de Dom Casmurro. Tradução de Fábio Fonseca de Melo. Cotia, SP: Ateliê Editorial, 2008.

CHALHOUB, Sidney. "Para que servem os narizes? Paternalismo, darwinismo social e ciência racial em Machado de Assis". In: (Org.). Artes e ofícios de curar no Brasil. Capítulos de história social. Campinas, SP: Editora da Unicamp, 2003. . Machado de Assis, historiador. São Paulo: Companhia das Letras, 2007.

CONRAD, Robert. Os últimos anos da escravatura no Brasil: I850-I888. Tradução de Fernando de Castro Ferro. Rio de Janeiro: Givilização Brasileira, I978.

DAVIS, David Brion. O problema da escravidão na cultura ocidental. Tradução de Wanda Caldeia Brant. Rio de Janeiro: Givilização Brasileira, 200 I.

FAORO, Raymundo. Machado de Assis: a pirâmide e o trapézio. São Paulo: Globo, 2001 .

GLEDSON, John. Machado de Assis: Impostura e Realismo uma reinterpretação de Dom Casmurro. Tradução de Fernando Py. São Paulo: Companhia das Letras, I99I.

GUIMARÃES, Hélio Seixas. Os leitores de Machado de Assis: o romance machadiano e o público de literatura no século I9. São Paulo: Edusp, 20I2. (Coedição: Nankin).

HOBBES, Thomas. Leviathan, or, Matter, form, and power of a commonwealth ecclesiastical and civil. Cambridge: Cambridge University Press, I935.

MEYER, Marlyse. Caminhos do imaginário no Brasil. São Paulo: Edusp, 200 I.

NABUCO, Joaquim. Um estadista do Império. Rio de Janeiro: Topbooks, I997.

SCHWARCZ, Lilia Moritz. As barbas do Imperador: D. Pedro II, um monarca nos trópicos. São Paulo: Companhia das Letras, I998.

SCHWARZ, Roberto. Um mestre na periferia do capitalismo. São Paulo: Editora 34, 2000. (Coleção Espírito Grítico, coedição: Duas Gidades).

SILVA, Ana Cláudia Suriani. Machado de Assis: do folhetim ao livro. São Paulo: Editora Nversos, 2015 .

Laila Correa e Silva é graduada em História pela Universidade Estadual de Campinas.

lailacorreaesilva@gmail.com 